\title{
The Role of Facebook in Enhancement of Undergraduates' Receptive Skills at a Saudi University
}

\author{
Ahmad Qadi ${ }^{1}$ \\ ${ }^{1}$ Umm Alqura University, Saudi Arabia \\ Correspondence: Ahmad Qadi, Umm Alqura University, Saudi Arabia.
}

Received: June 21, 2021

Accepted: July 19, 2021

Online Published: July 26, 2021

doi: $10.5539 /$ elt.v14n8p19

URL: https://doi.org/10.5539/elt.v14n8p19

\begin{abstract}
Observing receptive skills development in Saudi Arabia's undergraduates at Summer University (pseudonym), this paper immaculately investigates students' perceptions regarding the uses of Facebook as a well-liked forum of social media pertinent to enhancement of Receptive Skill of English, as a foreign language. At greater extent, their approaches have been scrutinized while using Facebook and the nature of influence of Facebook have been examined as well. Data have been collected from seventy-five undergraduate's students via questionnaire. In addition, findings put forward that Facebook use is exceedingly effectual in mounting students' listening and reading skills meticulously of English language. Relevantly, some of the probable threats to students' proficiency have been pointed out. In fewest possible words, the study lucidly concludes that undergraduates, generally speaking, are positive in relation to the role of Facebook in the development of receptive skills while using Facebook, which not only influencing undergraduates to visualize innovative ideas in visual or video formats but also it inspires to communicate in English language.
\end{abstract}

Keywords: receptive skills, enhancement, Facebook use, probable threats, innovative ideas

\section{Introduction}

The uses of "Social Media" have become progressively more entrenched in daily life. Among various Social media, Facebook is an interactively socio-virtual communication tool or web-based consumer-generated collaboration of knowledge (Blake, 2016). It has become popular gradually in students' communities. This platform could be equally used for formal as well as informal eruditions. Nevertheless, Facebook is recurrently used by not only students but also adults these days as a source of edutainment (education and entertainment) or impacts on their learning (Namaziandost \& Nasri, 2019). It plays pivotal roles in enhancing basic receptive skills (Al Momani, 2020). Besides, Facebook is one of the Social Media sources via which public are linked with one another across the globe or creates a highly communicative linguistic context (environment) (Black, 2005). People frequently share their thoughts, emotions and views through its application all over the world. Also, it is one of the online social networking websites. Greatly, it renders a platform for building social relationships among people. According to Krashen's (1994) argument of "The pleasure hypothesis" which projects categorically that "comprehensible input" impacts upon the production of language. The pleasure hypothesis through this way, it might act as a connecting source for linking people in social contexts with each other.

By linking them together, they profoundly get into the minds and hearts of one another; it permits the sharing of user-generated contents by means of creations and exchanges (Kaplan \& Haenlein, 2010). They sort out the inner feelings and sentiments to one another. According to McLaughlin Lee (2008) has argued that SM use has the socio-constructive learning approach Even, people, who are illiterate in modern society, use Facebook [henceforth FB] for dissimilar purposes for instance writing comments, uploading videos and photos or sharing images having the intentions of sharing (Evans, 2012). Today's learners are immensely defiant to outmoded learning and teaching methods (Bosch, 2009). Similarly, an individual or a group receives learning engagements and motivations via social media sites (Wamba \& Carter, 2016). In due course, their engagements augment analytical thinking, as well as independent learning (Malerba, 2011).

Attributable to such use of Facebook, essentially undergraduates have initiated the development of English receptive skills in their quotidian native language conversations. FB becomes increasingly fashionable among young undergraduates and particularly in the students' community at Summer University. They use it in group chats in which they discuss diverse academic debates and share an assortment of constructive propositions 
regarding topics with one another. As these communications are carried out, at maximum level, in the English language, so in due course, it influences English language receptive skills [henceforth RS] potentialities of the undergraduates' students. In addition, several of them at Summer University are experiencing positive impacts in term of enhancing their RS through the frequent use of FB. It promotes second language acquisition and learning (Thorne, 2008). They regard it as an effectual activity and never think about its futile impacts upon them. Consequently, the present research paper particularly ascertains the relationships between social media and students' RS efficiency.

RS become the indispensable nucleus of any language. They probably create challenging as well as lengthy part of learning of foreign language having the imparting knowledge through Social Media [henceforth SM] interactions that play fundamental role in their enhancement (George, 2018). It obtains time and surges like an invariable process, once RS fundamentals of a language get established such as basic grammar, pronunciation, and vocabulary, then the acceleration is usually observed in productive skills [henceforth PS] (speaking \& writing) of a language (Krashen, 1985). Initially, RS are the rudimentary knowledge for PS (Masduqi, 2016). All over this process, undergraduates become accustomed with the new lexicon, fragmentary utterances or junks while they use FB (Lomicka \& Lord, 2009). These language ingredients could play crucial roles to develop their aptitude of language learning through social media (Namziantost \& Nasri, 2019). The use of social networking is very fashionable among undergraduates at Summer University regarding English language. According to Evriklea Dogoriti, Pange Jenny, and Anderson Gregory (2014) have argued that social networking (as a tool) can help out not only teachers but also learners to access contemporary information and facilitate English learning. Individuals construct their own textual voice/s (Blake, 2016). The main focus of the present work is to study the relationships between SM, especially Facebook, and RS influence the growth of PS of undergraduates' English language, particularly at the college (intermediate) level. This research also highlights the impacts of Facebook on the growth and development of RS of English language of the students. Significantly, it avoids over-reliance on the instructor in higher education (Tess, 2013).

\section{Literature Review}

The historical backdrops of EFL teaching have witnessed a great number of changes in planning, procedures, and strategies to facilitate its learners, however in contemporary era the roles of teachers become less responsible due to widespread use of SM. Notwithstanding these, the objectives have constantly been changed that are making learners of EFL communicatively capable in the target language as well as shaping their level of proficiency to encounter the various challenges in real situations of their life (Nasri, Biria, \& Karimi, 2018). Without a doubt, SM uses enhance awareness that flourishes foreign language components comprehension via the development of grammar, reading, vocabulary, writing, listening, speaking skills and pronunciation skills (Levy, 2009; Namaziandost \& Shafiee, 2018). Therefore, involving SM in for enhancing language skills become an educational paradigm which enable the learners to develop listening and reading skills; they are need on urgent bases (Aziz, Shamim, Aziz, \& Avais, 2013). More to the point, evidences have depicted those learners who have experienced SM for their improving English are comparatively better in performance rather than those have worked in traditional settings for learning of a second language (Akinola, 2015; Pichette, 2009). Correspondingly, foreign language education requires equipping learners with the present needs by means of providing tools and skills that enable its lanners competent of dealings with current emerging requirements effectively (Haigh, 2010).

\section{Methodology}

A group of 75 Undergraduates at Summer University, who were studying at three different semesters third, fourth and fifth respectively had selected for the present study. Their participation also was voluntary. The group of undergraduates belonged to different disciplines and with varying levels of proficiency in English.

\subsection{Sample}

For the current study, the researcher chooses the stratified sampling technique (SST). The number of 25 students from third and forth semesters was selected by picking each of the twelfth students by marking them from their attendance list from undergraduates' classes correspondingly. The same procedure was pursued in fifth semester and fifteen students were selected. Thus seventy-five students selected from three different semesters comprised the population of the current research study.

\subsection{Date Collection}

Data have collected via the questionnaire consisting of five questions. They were a combination of comprising dichotomous (yes/no) and rating scales of a three-point, five-points, and a seven-point respectively. Questions 
were created to scrutinize undergraduates' perceptions, approaches, and nature of FB use in connections to RS enhancement as a foreign language.

\subsection{Data Analysis}

Data have collected from the undergraduates at Summer University through the tool of questionnaire, was in tabulated. Each response of the participants (undergraduates) was presented with the number of participants. Findings presented in percentages, ratios as well as the results were interpreted and analyzed accordingly. Conclusions were drawn and recommendations were suggested.

\section{Data Presentation}

The current study consists of some major findings attained from undergraduates' responses gathered via questionnaire. The analyses of the results in this section are discussed in one smallest and two major sections. The first section (1) describes in brief undergraduates' academic year and the number of them studying in the different academic years of their graduation. The second section (2) contains an analysis of the different aspects of FB use by the undergraduates. Connectively, the final third (3rd) section argues the use of FB in relation to undergraduates' RS enhancement of EFL learning. Before discussing undergraduates' responses concerning their perceptions and approaches to the use of $\mathrm{FB}$, classification of undergraduates based upon their academic year is presented. It is to accentuate and underscore the fact that the use of FB was evenly well-liked among undergraduates from various academic disciplines and educational backgrounds of the above-stated semesters third, fourth and fifth undergraduates respectively.....

Table 1. Undergraduates' Classification on Academic Basis

\begin{tabular}{llll}
\hline No & Academic year & Number of Students & $\mathbf{\%}$ \\
\hline $\mathbf{1}$ & $3^{\text {nd }}$ semester & 25 & 08 \\
$\mathbf{2}$ & $4^{\text {rd }}$ semester & 25 & 42 \\
$\mathbf{3}$ & $5^{\text {th }}$ semester & 25 & 03 \\
\hline
\end{tabular}

\subsection{Students' Academic Background}

\subsubsection{Section 1}

The academic classification of the undergraduates is given in the above table illustrates that they were from three separate academic disciplines. It is vital to explicate at this juncture to delineate each of the three semesters (academic levels) and sub-levels of the undergraduates being the participants of this study. The first two categories, explicitly, third and forth semester are the junior as well as senior semesters of the university level. It comprises undergraduates who were having their second year of their higher education at the institution. Likewise, the next one category of fifth semester refers to undergraduates who were having their third year of their university career respectively. This fifth semester comes under the half-graduation level. Then, the last category includes undergraduates who were from the academic discipline of B.S honors. It contains undergraduates studying in five-year graduation program which has one extra year comparatively than B.S level. For all undergraduates, the language of instruction belonging to these three semesters, as mentioned above, academic disciplines was English. Furthermore, English was included as a mandatory subject in their course contents.

The majority of the undergraduates enquired in this study who were the students studying at the mid-level of the university. They include (25) students having their third semester and (25) students who were having their second year of higher education. They make $66.6 \%$ of all the students: $08 \%$ of students were from the second semester and $48 \%$ of the third semester. The next category comprises of students studying at fifth semester. In this category, 25 students were i.e. they were having the third year of their university life, and one semester senior to the previous semesters. The remaining twenty-five students were studying at B.S hons. They were students from five semesters B.S make 33.3\% of the total students who partook in the present study. The total number of students was seventy-five.

\subsubsection{Section 2}

\section{The Use of FB: Various Aspects Undergraduates' use of FB on Daily Basis}

All the undergraduates were frequent users of FB. They were using FB app on their smart-phones, laptops, computers, and tabs. So as to ensure their usage of FB and determine the spending average time on using it, they were given dissimilar options to mark in accordance with their habitual practices which increase RS 
enhancement. The subsequent is the summary of the number of undergraduates who were divided into groups on the basis of their average spending time while using FB on daily basis.

Table 2. Undergraduates' Duration of FB Use on Daily Basis

\begin{tabular}{llll}
\hline No & Duration Spent & Number of Undergraduates & \% \\
\hline $\mathbf{1}$ & Less than one hour & 25 & 38.46 \\
$\mathbf{2}$ & One and a half hours to two hours & 22 & 31.76 \\
$\mathbf{3}$ & Up to three hours & 12 & 16.38 \\
$\mathbf{4}$ & Up to four hours & 07 & 10.76 \\
$\mathbf{5}$ & More than five hours & 05 & 7.69 \\
$\mathbf{6}$ & None of these & 00 & 00
\end{tabular}

The presented table illustrates us the undergraduates' responses indicating the average time they spent using FB on daily basis. It verifies the fact that entire undergraduates were using FB daily. There was no exception though the duration of time they spent while using FB was having variations. Among them, there was no undergraduate not using FB on daily basis. They were inculcated by the researcher to declare that time only they spent using FB utterly as well as not to mention that time they spent while using other applications.

The majority of the undergraduates are (25) who were using FB for less than one hour on daily basis. They form $38 \%$ of the entire participants. Then, the greater number of undergraduates comprised of that group using FB for one and half hours to two hours on daily basis. They were twenty-two in number and form $31.76 \%$ of the entire number of undergraduates. Next, $16.38 \%$ of the undergraduates (12) were using FB for up to three hours on daily basis. Seven of them forming (10.76\%) were using FB for up to four hours. Finally, the least number of undergraduates were using FB for the greatest time. They were seven in number forming (10.67\%). They used to spend using FB for more than four hours on daily basis. As abovementioned, none of the undergraduates neglected the use of FB on daily basis.

\subsubsection{The Motive behind Using FB}

One of the article objectives is to reveal the motives that influence undergraduates to use FB site. The researcher has identified five foremost reasons for FB uses given as subsequently:

1) Social Interactions and relationship managements;

2) Passing-time;

3) Amusements and diversions;

4) Companionships;

5) Communications;

All of the aforesaid five major motives were mentioned in the questionnaire and undergraduates were asked to select the one which they believe the most truthful for their FB use leading to augment RS of English language. Also, their replies are presented consequently.

Table 3. Undergraduates' Motives or FB Use

\begin{tabular}{llll}
\hline No & Motives & Number of Undergraduates & \% \\
\hline $\mathbf{1}$ & Social Interactions & 34 & 51.23 \\
$\mathbf{2}$ & Passing time & 16 & 24.07 \\
$\mathbf{3}$ & Entertainment & 32 & 49.23 \\
$\mathbf{4}$ & companionship & 12 & 17.38 \\
$\mathbf{5}$ & Communication & 36 & 55.38
\end{tabular}

The finding of the study uncovers that out of 75 undergraduates, 34 numbers of them use FB to keep social interactions with friends. Next, 16 undergraduates primarily use FB to pass time when they think being bored. This identifies the ideas of socialization with associates online. Discussing regarding entertainment, the findings illustrate that 32 numbers of undergraduates consider that FB is one the sources of entertainment. It has the function to assist companionship or does the work of facilitation in continuation of companionship. Due to this function, 12 respondents used FB to experience long-lost friends. Besides, FB also operates chiefly as a tool for 
communicative purposes among undergraduates. Hence, 36 respondents stated that FB was used to send messages as well as share information with their acquaintances. The use of "messages on FB can be economizing by means of time and money. It is one of the best ways to share information or ideas with one another leading the acceleration of RS of English language.

\subsubsection{Nature of Usage of Apps in Facebook}

The next finding is relevant to another aspect of FB used by the undergraduates. It was scrutinized the nature of the usage of application on FB. Undergraduates were presented with ten major apps that are used in FB developing their RS. These applications include:

1) Update Videos;

2) Play Video Games;

3) Poke Friends for Fun;

4) Update Status;

5) Upload photographs;

6) Take Survey or Quiz on Friends;

7) Posting an opinion/s/ a thought/ a statement;

8) Comments on Friends' Post;

9) Conversation with Friends;

10) Studying various Materials in English.

Undergraduates were asked to choose by marking any of the given options which they find appropriate to their FB use increasing their RS of English language. Results pertinent to these questions are illustrated in the subsequent table followed by its analysis respectively.

Table 4. Nature of the Undergraduates' Usage of Different Applications

\begin{tabular}{llll}
\hline No & Usage of Applications & Number of Undergraduates & $\%$ \\
\hline $\mathbf{1}$ & Update Video/s & $\mathbf{2 4}$ & $\mathbf{3 4 . 8 4}$ \\
$\mathbf{2}$ & Play Games & $\mathbf{1 2}$ & $\mathbf{1 6 . 3 8}$ \\
$\mathbf{3}$ & Poke Friends for Fun & $\mathbf{2 1}$ & $\mathbf{4 7 . 1 5}$ \\
$\mathbf{4}$ & Upload Photographs & $\mathbf{4 0}$ & $\mathbf{5 9 . 4 6}$ \\
$\mathbf{5}$ & Update Status & $\mathbf{3 2}$ & $\mathbf{4 5 . 1 5}$ \\
$\mathbf{6}$ & Take Quiz/es/Survey/s on Friends & $\mathbf{1 9}$ & $\mathbf{2 7 . 1 5}$ \\
$\mathbf{7}$ & Post an opinion/s a thought/s statement/s & $\mathbf{2 1}$ & $\mathbf{3 2 . 3 0}$ \\
$\mathbf{8}$ & Commenting Friends' Post/s & $\mathbf{3 9}$ & $\mathbf{5 7 . 4 3}$ \\
$\mathbf{9}$ & Conversation with Friends & $\mathbf{3 5}$ & $\mathbf{5 5 . 9 2}$ \\
$\mathbf{1 0}$ & Studying different materials in English & $\mathbf{6 3}$ & $\mathbf{7 1 . 7 8}$
\end{tabular}

Results demonstrated in the above table that out of seventy-five undergraduates, $34.84 \%$ of undergraduates prefer to update video/s frequently along with using several of the other apps on FB. Subsequently, $16.38 \%$ of undergraduates are fond to play games. They kept this entertainment generally on FB. Then, twenty-one of the undergraduates (47.15\%) use FB to poke friend/s for enjoyment along with a number of other apps on FB. The majority of undergraduates (59.45\%) adore uploading photographs on FB. After that, $45.15 \%$ of them like to update their statuses as well as have opinions of the friends on it. More to the point, the next $27.15 \%$ of undergraduates are keen to take survey or quiz of informative purposes on FB. In addition, 32.30\% of them find themselves irresistible to post their opinions, statements and thoughts. A substantial number of them, $(59.46 \%)$ undergraduates love commenting on friends' posts. Correspondingly, 55.92\% of them prefer chatting with friends while using FB. Last of all, $71.78 \%$ of undergraduates responded that they prioritize to study different materials in English being shared on FB respectively leading to their augmentation of RS. 


\subsubsection{Section 3}

\section{Undergraduates' RS Enhancement Opinions \& Focused Areas Regarding FB Use}

The next finding uncovered is directly FB use related to Undergraduates' English language RS improvements that leads to proficiency PS accordingly. To come across about how undergraduates promote from the use of FB by means of accentuating, improving, and raising their RS of English language at Summer University. They had given six statements. Each one explicates an aspect of RS enhancement categorically. The subsequent are the skills that were stated to the undergraduates' in the questionnaire:

1) Reading habits;

2) Communication skills;

3) Vocabulary enrichment;

4) Writing skills development;

5) Improving spellings corrections;

6) Grammar improvement;

Undergraduates had instructed to mark English language skills that they primarily focus on while using FB. They had to choose by marking any of the given six options to them. They were given an option in case of no skill focused. Their responses are stated in the given table below, as well as followed by its analysis.

Table 5. Language Area Mainly Focused on Undergraduates

\begin{tabular}{llll}
\hline NO & Skill Focused & Number of Undergraduates & $\%$ \\
\hline 1 & To grow my reading habits & $\mathbf{4 8}$ & $\mathbf{7 3 . 8 4}$ \\
2 & To enhance my communication skills & $\mathbf{3 3}$ & $\mathbf{5 0 . 7 6}$ \\
3 & To accelerate English vocabulary & $\mathbf{6 0}$ & $\mathbf{9 2 . 3}$ \\
4 & To develop my writing skills & $\mathbf{2 7}$ & $\mathbf{4 1 . 5 3}$ \\
5 & To make accurate \& improve my spellings & $\mathbf{5 0}$ & $\mathbf{7 6 . 9 2}$ \\
6 & To focus \& increase my knowledge of grammar & $\mathbf{3 5}$ & $\mathbf{5 3 . 4 8}$ \\
$\mathbf{7}$ & None of the above & $\mathbf{1 0}$ & $\mathbf{1 5 . 3 8}$
\end{tabular}

Results of the displayed table demonstrate the purposes of developing the both RS and PS mainly accentuated by the undergraduates during their FB use. The majority of the undergraduates $(53.48 \%)$ were replied that they mostly concentrate on grammar or its related contents. Undergraduates who primarily focus on grammar while using FB were thirty-five in number. It means that rarely half of them largely centralize on grammar in their FB use. Next, the greatest number (60) of the undergraduates mainly focuses on vocabulary of English. They benefit from FB use to enrich English vocabulary. They form $92.3 \%$ of the total participants. The second-largest number of the undergraduates' group consists of fifty participants who had replied that they focus on their spelling accuracy and improvement while using FB. They were of the view that FB helps them improve their spelling corrections leading to better writing or more refinement. When they practice expressing their views, comments, and write status updates, they prioritized observing spelling accuracy. They were $96.92 \%$ of the total participants who participated in this study. The fourth group contains twenty- 27 undergraduates which is $41.53 \%$ of the total number. They replied that they concentrate upon their writing expressions while writing or performing various tasks on FB. The next category consists of forty-eight students who use FB to enlarge their reading habits on FB. In their views, their skills of reading are enhanced and got betterment when they read the quotes status updates, utterances, articles, comments of other users, and other reading stuffs written in English on FB. Lastly, five undergraduates $(7.69 \%)$ had refuted all the alternatives resented to them.

\subsection{Approaches to FB Pertinent to RS of English Language}

The next set of questions additionally scrutinizes undergraduates' approaches as well as tendencies of different sorts concerning their RS enhancement of English language or their proficiency while using FB. The subsequent list of questions consists of nine questions in total that were planned to be answered in 'Yes/No' by the undergraduates. The presented table below highlights the undergraduates' replies to these questions as: 
Table 6. Students' Opinions about Facebook use and English Language

\begin{tabular}{|c|c|c|c|c|c|}
\hline No & Question & Response in yes & Yes $\%$ & Response in no & No $\%$ \\
\hline 1 & $\begin{array}{l}\text { Do you become less cautious of spelling } \\
\text { and grammar while chatting or writing } \\
\text { on FB? }\end{array}$ & 38 & 58.46 & 25 & 40.53 \\
\hline 2 & $\begin{array}{l}\text { Do you use abridged words, phrases, } \\
\text { sentences or other shortcuts? }\end{array}$ & 50 & 76.92 & 23 & 30.07 \\
\hline 3 & $\begin{array}{l}\text { Do your FB friends comprehend these } \\
\text { reduced words, phrases, sentences, or } \\
\text { other shortcuts? }\end{array}$ & 54 & 83.07 & 18 & 27.04 \\
\hline 4 & $\begin{array}{l}\text { Do you prefer abbreviated style of } \\
\text { language due to its time-saving factors? }\end{array}$ & 48 & 73.84 & 17 & 26.15 \\
\hline 5 & $\begin{array}{l}\text { Do you sometimes use shortcut/s used in } \\
\text { FB in your academic writing or } \\
\text { professional tasks? }\end{array}$ & 52 & 80.00 & 19 & 30.00 \\
\hline 6 & $\begin{array}{l}\text { When you read messages or watch } \\
\text { videos on FB of your friends in English, } \\
\text { do you think that these influence your } \\
\text { RS (reading and listening skills) as much } \\
\text { information as possible? }\end{array}$ & 48 & 73.84 & 19 & 27.25 \\
\hline 7 & $\begin{array}{l}\text { Are you constantly willing to discover } \\
\text { new words, utterances or symbols used } \\
\text { by other FB users? }\end{array}$ & 44 & 67.69 & 20 & 31.6 \\
\hline 8 & $\begin{array}{l}\text { Do you think that FB enhances } \\
\text { Receptive skills (listening \& reading)? }\end{array}$ & 58 & 79.84 & 17 & 26.15 \\
\hline 9 & $\begin{array}{l}\text { Do you think that FB influences you to } \\
\text { concentrate on words and expressions } \\
\text { surging RS? }\end{array}$ & 45 & 69.22 & 30 & 46. 15 \\
\hline
\end{tabular}

Subsequent is the discussion upon results of the set of all nine questions:

Answer to the first question in the table that was asked from the undergraduates examines whether they become less vigilant of grammar plus spellings when they converse or write on FB thirty-eight that forms (58.46\%) of the undergraduates affirmed that they do become less cautious - though not completely-while chatting or writing on FB. The remaining twenty-seven (40.53\%) them replied that they do not become less careful of grammar plus spellings while using English on FB. Subsequently, the next question in the list is regarding the use of abridged words, phrases sentences, and shortcuts while using FB. In reply to this, the majority of the undergraduates $(76.92 \%)$ divulged that they use condensed grammatical units (words, phrases, and other shortcuts) on FB in their writings. Similarly, the section of undergraduates who were thirty in number twenty-three forming (30.07\%) denied abbreviations uses and other shortcuts in their writings.

Subsequently, the third question is a supplementary to the former question asked (2). It was posed to enquire if the abbreviations and other shortcuts in writings of the undergraduates are comprehended by the other FB users. The majority of them are eighty-three in numbers $(83.07 \%)$ responded that abbreviations and other shortcut-forms in their writings are comprehended by the other FB users i.e. their friends and other associates. The remaining eighteen $(27.04 \%$ ) had replied that abbreviated and shortcut forms are not effortlessly understood by other FB users. They have to expound these abbreviated and shortcuts.

Sequentially, question number fourth was related to the former two questions. It was asked to discern the reasons for using abridged language. Undergraduates were inquired whether they use for time-saving abbreviated forms of language. Majority of them (73.84\%) had assigned the use of shortened language due to time saving reasons. the seventeen students $(26.15 \%)$ refuted the stance of using the condensed language for the sake of time economization. The next question also raises the serious issues of the achievements of FB to use for academic writings of the undergraduates. They were asked if they use the reduced language or other -forms in writings on FB in their academic writings as well. Despite the fact that the number of undergraduates (52) rejected the uses 
of curtailed language in their academic writings as the effects of FB use, nine-teen (30\%) had acknowledged the fact that their academic writings are influenced by the use of FB when they make the use of condensed language in their academic writings leading realizing as professional development.

Respectively, sixth question refers to reading and listening being shared by their associates via writings on the wall of a FB page, or throughout video clips status updates. Most of the respondents (73.84\%) stated that they both reading and writing are being influenced via the communicated information by their associates FB. The rest of the students $(27.25 \%)$ which were seventeen in number replied that they are not being influenced in terms of RS enhancement. likewise; question (No. 7) examines undergraduates' interests in enrichment of themselves by new lexicon, functional expressions and special types of symbols used in the writings of other FB users. Amid the participants, forty-four forming $(67.69 \%)$ replied that their interests increase in learning new expressions, words along with understanding the significant meanings of symbols and attached sentiments used by other FB users in their writings on FB. On the contrary, the rest of twenty-one forming $(31.30 \%)$ undergraduates presented their disagreement with of such experiences leading to such RS empowerment via FB.

Correspondingly, questions no. 8 is pertinent to undergraduates' general perceptions concerning RS enhancement having the impacts via FB. They were also asked if they come across FB useful in improving or learning RS of English language being academes. The majority of them were of the opinion that FB influences them in learning English a foreign language. Results indicate that fifty-eight forming (79.84\%) of the undergraduates considered it helpful in this regard. While seventeen forming $(26.15 \%)$ believed that it does not influence them in any respects in learning English as a foreign language. Evenly, no. question (9) is concerning the possible concentration upon frequent words and expressions of FB in learning the EFL. Undergraduates were asked whether FB causes the uses of grammatically correct words and expressions along with spellings. Results, in the table, illustrate that the majority of them which forty-five in numbers forming $(69.22 \%)$ of the total percentage. They were at the opinions that it influences them to use grammatically accurate words, spellings as well as expressions. The remaining thirty undergraduates forming $(46.15 \%)$ had disagreed with the former thoughts of other participants.

\section{Conclusion and Recommendations}

\subsection{Conclusion}

To summarize, the entire participants of present study were found to be FB users; the propensity of using it was recorded confirming different experiences via the use of FB as a part of their every day's routine. While not recommended some of the undergraduates were using it for the approximately equivalent durations. Besides, the over-use of it might overshadow the concentration given to other subjects and activities having pertinence to RS enhancement. The main motives behind undergraduates' use of FB in this study were the influences of it on their improvement of English language reading and listening. It could be assigned to the fact that text messages/ing, sending or uploading photos, audios, and files, and making calls on FB cause in acceleration of RS. Yet, the nature as well as purposes requires further research to ensure the fact whether it contributes to undergraduates' expressiveness and proficiency. The other major two motives recognized behind their use of FB were social interactions, companionship, and entertainment. Some undergraduates at Summer, yet, marked the contradiction with the majority of the other respondents. Measuring the relative effects of each motive of FB use by them is a broad area subject to further research study. Investigating more into the nature of applications used by them of FB, it was known that the majority of them were using the applications of reading posts and commenting upon the status updated by FB users, from this study perspectives the latter is significant in augmenting RS of English as an EFL.

The third mainly used application is chatting with friends from which undergraduates read and discuss grammatical items leading to influencing their RS. Similarly, a sizable portion of undergraduates affirmed that they access and read dissimilar sorts of materials written in English. It directly adds to the development of their RS habits. The fashion of posting opinions as well as updating status becomes beneficial in enhancing their PS of English language. Talking particularly about the areas or skills that were focused on by undergraduates while using FB, they develop communication skills, and improving grammar via input. Besides, English vocabulary and writing skills enrichment impact positively upon reading habits that were given priority likewise. Neglecting all the six areas of English language by fewer undergraduates though questions the utility of FB use with regard to RS English language. Lack of care about grammar, spellings, using abbreviations and shortcuts have been observed the major concerns identified in present paper. On the other hand, a greater section of undergraduates substantiated the assumptions that they concentrate upon new lexicon, symbols, expressions and videos they 
come across using FB accelerate their RS of English language categorically. On the whole, the majority of the undergraduates believed that FB facilitates them in RS enhancement of English as a foreign language.

\subsection{Recommendations}

The researcher suggests the subsequent recommendations for facilitating RS enhancement of English as a foreign language through FB use in light of this study. They are stated as under:

$>$ Measures should be adopted by undergraduates to access more pages of FB having sharing of reading passages and video clips for overall development of RS performance.

$>$ An awareness campaign should be initiated to draw attention to the effectiveness of FB to undergraduates RS enhancement and learning English language by policy-making and instructors.

> Undergraduates should be persuaded to like and follow FB pages created to improve RS particularly of English language.

> Holding discussions and language learning tasks and activities on FB should be created the part of the co-curricular activities by instructors to enhance the RS as well as PS leading to communication skills betterment of the undergraduates.

$>$ The practice of selecting different sorts of assignments and giving proper feedbacks on those assignments should be adopted to motivate FB users for educational purposes and progress of English language skills.

> Undergraduates writing should be meticulously checked for using abbreviations as caused by FB and this practice should be strictly discouraged by instructors.

\section{References}

Akinola, O. T. (2015). Social media as a weapon mass instruction in training library and information science. In A. Tella (Ed.), Social Media Strategies for Dynamic Library Service Development (pp. 175-202). IGI Global. https://doi.org/10.4018/978-1-4666-7415-8.ch010

Al Momani, A. M. (2020). The Effectiveness of Social Media Application "Telegram Messenger" in Improving Students' Reading Skills: A Case Study of EFL Learners at Ajloun University College/Jordan. Journal of Language Teaching and Research, 11(3), 373-378. https://doi.org/10.17507/jltr.1103.05

Aloraini, S. (2012). The impact of using multimedia on students' academic achievement in the College of Education at King Saud University. Journal of King Saud University -Languages and Translation, 75-82. https://doi.org/10.1016/j.jksult.2012.05.002

Aziz, S., Shamim, M., Aziz, M. F., \& Avais, P. (2013). The Impact of Texting/SMS Language on Academic Writing of Students- What do we need to panic about? Elixir International Journal, 12884-12890.

Black, R. W. (2005). Access and affiliation: The literacy and composition practices of English-language learners in an online fanfiction community. Journal of Adolescent \& Adult Literacy, 49(2), 118-128. https://doi.org/10.1598/JAAL.49.2.4

Blake, R. (2016). Technology and the four skills. Language Learning \& Technology, 20(2), 129-142.

Bosch, T. E. (2009). Using online social networking for teaching and learning: Facebook use at the University of Cape Town. Communication: South African Journal for Communication Theory and Research, 35(2), 185-200. https://doi.org/10.1080/02500160903250648

Dogoriti, E., Pange, J., \& Anderson, G. S. (2014). The use of social networking and learning management systems in English language teaching in higher education. Campus-Wide information systems. https://doi.org/10.1108/CWIS-11-2013-0062

Evans, D. (2012). Social media marketing: An hour a day. John Wiley \& Sons.

George, M. S. (2018). Developing listening and reading skills through social media using apps. Literary Studies, III, 93-101.

Haigh, P. (2010). Social Network Websites: Their Benefits and Risks. London: Optimus education e-books.

Kaplan, A. M., \& Haenlein, M. (2010). Users of the world, unite! The challenges and opportunities of Social Media. Business horizons, 53(1), 59-68. https://doi.org/10.1016/j.bushor.2009.09.003

Krashen, S. (1994). The pleasure hypothesis. Georgetown University roundtable on Languages and Linguistics 1994. Washington DC: Georgetown U. Press. 
Levy, M. (2009). Technology in use for second language learning. The Modern Language Journal, 93(1), 769-782. https://doi.org/10.1111/j.1540-4781.2009.00972.x

Lomicka, L., \& Lord, G. (2009). Introduction to social networking, collaboration, and Web 2.0 tools. In L. Lomicka \& G. Lord (Eds.), The next generation: Social networks and online collaboration in foreign language learning. San Marcos, TX: CALICO.

Malerba, M. L. (2011). Social Networking in Second Language Learning.

Masduqi, H. (2016). Integrating receptive skills and productive skills into a reading lesson. In Proceeding of the International Conference on Teacher Training and Education, 2(1), 507-511.

Mclaughlin C., \& Lee, M. J. W. (2008). Future learning landscapes: Transforming pedagogy through social software. Retrieved from https://nsuworks.nova.edu/cgi/viewcontent.cgi? Article=1044\&context=innovate

Namaziandost, E., \& Nasri, M. (2019). The impact of social media on EFL learners' speaking skill: a survey study involving EFL teachers and students. Journal of Applied Linguistics and Language Research, 6(3), 199-215.

Nasri, M., Biria, R., \& Karimi, M. (2018). Projecting Gender Identity in Argumentative Written Discourse. International Journal of Applied Linguistics \& English Literature, 7(3), 201-205. https://doi.org/10.7575/aiac.ijalel.v.7n.3p.201

Paliktzoglou, V., \& Suhonen, J. (2014). Facebook as an assisted learning tool in problem-based learning: The Bahrain case. International Journal of Social Media and Interactive Learning Environments, 2(1), 85-100. https://doi.org/10.1504/IJSMILE.2014.059694

Tess, P. A. (2013). The role of social media in higher education classes (real and virtual)-A literature review. Computers in human behavior, 29(5), A60-A68. https://doi.org/10.1016/j.chb.2012.12.032

Thorne, S. L. (2008c). Transcultural communication in open internet environments and massively multiplayer online games. In S. Magnan (Ed.), Mediating discourse online (pp. 305-327). Amsterdam: Benjamins. https://doi.org/10.1075/aals.3.17tho

\section{Copyrights}

Copyright for this article is retained by the author(s), with first publication rights granted to the journal.

This is an open-access article distributed under the terms and conditions of the Creative Commons Attribution license (http://creativecommons.org/licenses/by/4.0/). 